Research Article

\title{
Core Design of a Small Pressurized Water Reactor with AP1000 Fuel Assembly Using SRAC and COBRA-EN Codes
}

\author{
Van Khanh Hoang (iD \\ Institute for Nuclear Science and Technology (INST), Vietnam Atomic Energy Institute (VINATOM), 179 Hoang Quoc Viet, \\ Cau Giay, Hanoi 100000, Vietnam \\ Correspondence should be addressed to Van Khanh Hoang; hvkhanh21@gmail.com
}

Received 21 August 2020; Revised 19 October 2020; Accepted 31 October 2020; Published 11 November 2020

Academic Editor: Leon Cizelj

Copyright ( 92020 Van Khanh Hoang. This is an open access article distributed under the Creative Commons Attribution License, which permits unrestricted use, distribution, and reproduction in any medium, provided the original work is properly cited.

This paper presents the core design and performance characteristics of a $300 \mathrm{MWt}$ small modular reactor (SMR) with fuel assemblies of the AP1000 reactor. Numerical calculations have been performed to evaluate a proper active core size and core loading pattern using the SRAC code system with the JENDL-4.0 data library and the CORBRA-EN code. The calculated temperature coefficients including fuel temperature, coolant temperature, and isothermal temperature coefficient provide adequate negative reactivity feedbacks. The thermal-hydraulic analysis reveals acceptable radial and axial fuel element temperature profiles with significant safety margin of fuel and clad surface temperature. A safety analysis using the CORBRA-EN code shows that the core will remain covered during the entire transient procedure of the fast transient of remarkably increasing power that would be caused by the ejection of control rod. The analysis results indicate that the core with a cycle length of 2.22 years is achievable while satisfying the operation and safety-related design criteria with sufficient margins.

\section{Introduction}

In the recent years, the small modular reactors (SMRs), newgeneration reactors designed with an electrical output up to $300 \mathrm{MWe}$, have been received increasing attention within the nuclear energy community due to a number of advantages $[1,2]$. Because of the small size, the SMRs require less capital investment and construction time compared to traditional commercialized reactors, so that financial risks could be reduced. The SMR designs can adopt most of the advanced safety features of the current technologies. One of the advantages is that the components of the reactor system can be fabricated at factories and transported modularly to the plant site for installation. It also has greater scalability, and it is more flexible to choose locations for the SMRs than for the traditional large reactors. Therefore, it would be a suitable solution for a wide range of users and applications, for instance, remote areas with small electricity demand, heating, or hydrogen production application $[3,4]$. The SMRs are being developed for a number of principal reactors including advanced light water reactors, heavy water reactors, and the generation IV reactors such as hightemperature gas-cooled reactors (HTGRs), liquid-metal, sodium, and gas-cooled fast reactors (LMFR, SFR, GFR), and molten salt reactors (MSRs) [5].

About 50 SMR designs are being under developed worldwide for both electrical generation and nonelectrical application such as desalination of seawater, district heating, hydrogen production, and other processes of heat application. Among those, three industrial demonstration SMRs are in construction including CAREM (integral PWR with the output of 150-300 MWe) in Argentina, HTR-PM (HTGR) in China, and KLT-40S (compact PWR for a floating nuclear power plant) in Russia. The integral pressurized water reactor (IPWR) technology is one of the major near-term SMR designs, of which primary components are contained in the reactor vessel. The CAREM-25 reactor is an example of the IPWR technology. The CAREM-25, a prototype reactor with the power of $27 \mathrm{MWe}$, is under construction. Other designs of IPWRs are SMART (Korea), NuScale (US), mPower (US), and Westinghouse SMR (US). The IPWR of the Westinghouse Electric Company is based on a partial-height $17 \times 17$ 
fuel assembly used in the AP1000 reactor. This reactor utilizes passive safety systems and proven components from the AP1000 plant design. All primary components including the steam generator and the pressurizer are located inside the reactor vessel [6].

The $17 \times 17$ robust fuel assembly (RFA-2) has a long operational experience, used for the Westinghouse AP1000 design, and also demonstrated excellent fuel performance worldwide as follows $[7,8]$ :

The RFA-2 fuel assembly provides

Lower needed cycle costs

Increased fretting margin

Heat transfer improvements

Enhanced debris mitigation

Benefits of the RFA-2 fuel assembly are as follows:

Stiff structure for margin against fuel assembly distortion

High-contact area midgrids enhance margins-to-fuelrod fretting

Flow mixing grids increase departure from the nucleate boiling (DNB) margin

Multiple layers of defense against debris

Integral fuel burnable absorber for optimum fuel cycle economics

High-performance mixing vane grids

High-burnup advanced materials ZIRLO

Basing on the pervious findings, the purpose of the present work is to show a design of a small PWR core with a thermal output of $300 \mathrm{MWt}$ based on the AP1000 fuel assembly. Neutronic and thermal-hydraulic analyses have been performed to determine the core height, the number of fuel assemblies, and core configuration. The neutronic analysis has been conducted using the SRAC code system with the JENDL-4.0 library. Thermal-hydraulic analysis has been conducted with the CORBRA-EN code to investigate the safety parameters of the core. Reactivity coefficients regarding the change in temperature of fuel and coolant are also investigated to ensure the safety feature of the newly designed SMR core.

\section{Study Methodology}

The SRAC2006 code system [9] and the JENDL-4.0 nuclear data library [10] are used for performing the neutronic design process of the SMR core. The core burnup calculation process is divided into two steps. Firstly, cell burnup calculation using the PIJ module is conducted to produce few group burnup-dependent homogenized macroscopic cross sections. Secondly, the COREBN [11] is used for three-dimensional core burnup calculation based on the macroscopic cross section interpolation of the cell burnup calculation.

In order to confirm the core design criteria, thermalhydraulic analysis is performed to establish adequate heat removal capability of the design. In this study, the thermalhydraulic analysis is performed to ensure whether or not the
TABle 1: Main design parameters.

\begin{tabular}{lc}
\hline Design parameters & Values \\
\hline Reactor thermal power (MWt) & 300 \\
Reflector thickness & \\
Top (cm) & 25.4 \\
Bottom (cm) & 25.4 \\
Side $(\mathrm{cm})$ & 38.1 \\
Assembly pitch (cm) & 21.4173 \\
Fuel cell & \\
Pellet radius (cm) & 0.4096 \\
Inner clad radius (cm) & 0.4178 \\
Outer clad radius (cm) & 0.4750 \\
Fuel cell pitch (cm) & 1.2598 \\
Operating pressure (MPa) & 15.5 \\
Nominal inlet coolant temperature (K) & 553 \\
Nominal fuel temperature (K) & 1145 \\
Nominal moderator temperature (K) & 575 \\
\hline
\end{tabular}

reactor satisfies the desired design constraints. In the thermal-hydraulic model, conservation of mass, momentum, and energy-dependent equations are solved by using the COBRA-EN code [12]. Major parameters for the reactor are summarized in Table 1. For the core analysis, a whole fuel assembly and the associated coolant flow are treated as a single lumped-parameter channel. The whole core is represented by the $1 / 8$ sector due to its symmetrical configuration. Each channel contains an individual fuel assembly of 15 axial intervals, making up the lower triangular region of quarter-core and excluding the reflector. Although the thermal-hydraulic analysis is performed for the core model, in the critical heat flux (CHF) correlations of the COBRAEN code, there are some corrections that are applied, which correct the critical heat flux for various effects such as subchannels adjacent, nonuniform heat flux. As mentioned in [7], the difference between the design limit DNBRs and the safety analysis limit DNBRs results in the DNBR margin. A portion of this margin is used to unanticipated DNBR penalties. The DNBR limit, 1,45, is the appropriate DNB correlation limits increased to give sufficient margins to cover any DNBR penalties associated with the analysis.

The steady-state analysis is based on the reactor operating conditions. The required linear fission powers are based on the neutronic calculations as a result of the begin of cycle (BOC) of the reactor. In the COBRA-EN model, the CRTN model that is used for special applications with steady-state core simulators is applied. For the critical heat flux (CHF) correlation, the W-3 correlation [13] is selected for this study. The three-equation model with the EPRI void model is carried out. Furthermore, the properties of the fuel rod materials (density, conductivity, and specific heat of uranium dioxide and zircaloy) can be either input constant values or temperature-dependent correlations taken from MATPRO-11 [14] and implemented in the code.

For the transient analysis, the steady-state analysis is based on the reactor operating conditions and is followed by a fast transient of $1.5 \mathrm{~s}$. The power forcing function is a simple tent function with a four times the nominal operating power at $0.5 \mathrm{~s}$ and the end at $1.0 \mathrm{~s}$. A constant time step size at of $0.01 \mathrm{~s}$ is conservatively selected to restrict the power 
increase or decrease to a fixed rate of about $2.8 \%$ per time step.

The core design process consists of two steps as follows:

(a) Estimation of core size: the objective of this step is to determine the active fuel length and the number of fuel assemblies. Neutron transport calculations have been performed for an infinite core by imposing reflective boundary condition in the assembly level model. From the mass of uranium per assembly, the required number of fuel assemblies for the core can be determined. In this determination of core size, a four-year core lifetime, the average discharge burnup of $40 \mathrm{GWd} / \mathrm{t}$ with a single batch refueling scheme, and a capacity factor of 1.0 are conservatively assumed.

(b) Determination of the core loading pattern: once the required number assemblies are achieved, a symmetrical arrangement of the fuel assemblies in the active core zone is proposed for the initial core configuration. The core loading pattern is developed for the core design to meet the design criteria. Fuel assemblies with higher U-235 enrichment are selected with a high priority and located in the peripheral core locations to achieve a uniform power distribution and maximum fuel utilization. Finally, the core that meets the specified performance requirements is selected for further analysis.

\section{Core Design}

3.1. AP1000 Fuel Assembly Design. The typical fuel assembly, with $17 \times 17$ array, contains 264 fuel rods, 24 guide thimbles, and 1 instrumentation thimble as shown in Figure 1 [7]. The SMR core is designed with a thermal output of $300 \mathrm{MWt}$. The typical uranium oxide (UO2) fuel rods with $2.35,3.40$, and 4.95 wt.\% U-235 enrichments, used in the AP1000 reactor [12], are exploited in the current SMR design. The main design parameters and targets for the SMR are specified in Table 1. In the AP1000 reactor design, in order to control excess reactivity and flatten power distribution, burnable absorber rods and integral fuel burnable absorbers are also used. In this study, only fuel assemblies without burnable absorber are considered to design a new core. For the control element assemblies (CEAs), the standard 24-finger Ag-InCd (AIC) rod control cluster assembly is exploited for the current SMR design.

3.2. Safety Criterion. The primary core design goal for the SMR in this work is to achieve a long core without refueling and fuel enrichment within the industrial using 2.35, 3.40, and 4.45 wt.\% U-235 enrichments, used in the AP1000 reactor while satisfying other operation and safety-related design constraints. In order to achieve a uniform power distribution and maximum fuel utilization, the fuel assemblies with higher U-235 enrichment are selected with a high priority and located in the core center. Also, the fuel assemblies with lower U-235 enrichment are located peripheral core locations.

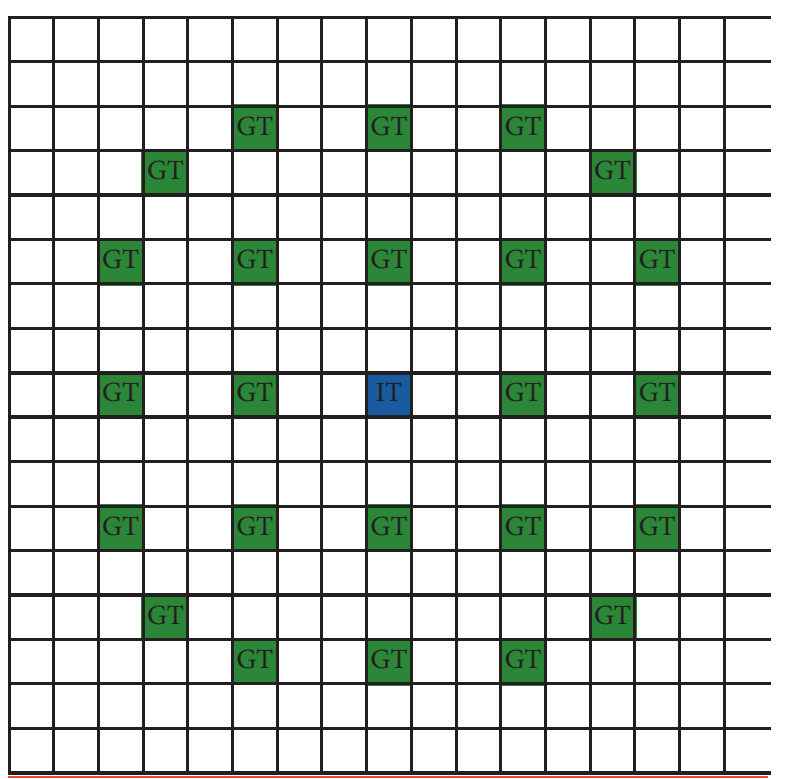

Figure 1: Locations of fuel rods, guide thimbles (GT), and instrumentation thimble (IT) in a fuel assembly.

For the purpose of conceptual development, design criteria of the AP1000 design including inherent safety, fuel coolability, and fuel integrity have been adopted for the current SMR design. The design criterion of negative temperature coefficients including Doppler, moderator temperature, and isothermal coefficients is essential for assuring inherent safety of the light water reactor. The design criteria for fuel coolability and fuel integrity are determined from the results of normal operation and transient analyses. In addition, the criterion of the power packing factor, minimum departure from the nucleate boiling ratio (MDNBR), and maximum critical boron concentration are also applied at the core outlet with consideration of the core pressure drop to prevent bulk boiling of the coolant. In order to shape the power profile and control the reactivity, the CEAs are needed for the design. In this study, the CEAs performance is analyzed without consideration of boric acid concentration in the coolant in both cold zero power (CZP) and hot full power (HFP) states to confirm whether or not to successfully shutdown the reactor. The design criteria are summarized in Table 2.

3.3. Determination of Core Size. In order to determine the active fuel length, a three-dimensional infinite core model has been developed based on an assembly level model using the SRAC code system. The model consists of an active fuel zone and two reflector zones at the top and the bottom. The AP1000 fuel assembly with the highest U-235 enrichment, i.e., $4.95 \mathrm{wt} . \%$, is selected for the active fuel zone. The reflective boundary condition is assumed for peripheral core, and the extrapolated boundary condition is set at the top and the bottom.

Figure 2 shows the evolution of the infinite neutron multiplication factor (k-inf) at the beginning of the cycle and the number of assemblies loaded into the core as functions of 
TABle 2: The design criteria.

\begin{tabular}{lc}
\hline Parameters & Values \\
\hline Maximum 3D PPF (Fxyz) (-) & $<2.60$ \\
Maximum 2D PPF (Fxy) (-) & $<1.59$ \\
DNB correlation (-) & $\mathrm{W}-3$ \\
MDNBR at nominal conditions (-) & $\geq 1.45$ \\
Maximum fuel temperature (K) & $<2867$ \\
Maximum clad temperature (K) & $<1478$ \\
Maximum critical boron concentration (ppm) & $<2700$ \\
Temperature coefficients (pcm/K) & $<0$ \\
CEAs performance & \\
Maximum k-eff over cycle for CZP (-) & $<1.0$ \\
Maximum k-eff over cycle for HFP (-) & $<1.0$ \\
\hline
\end{tabular}

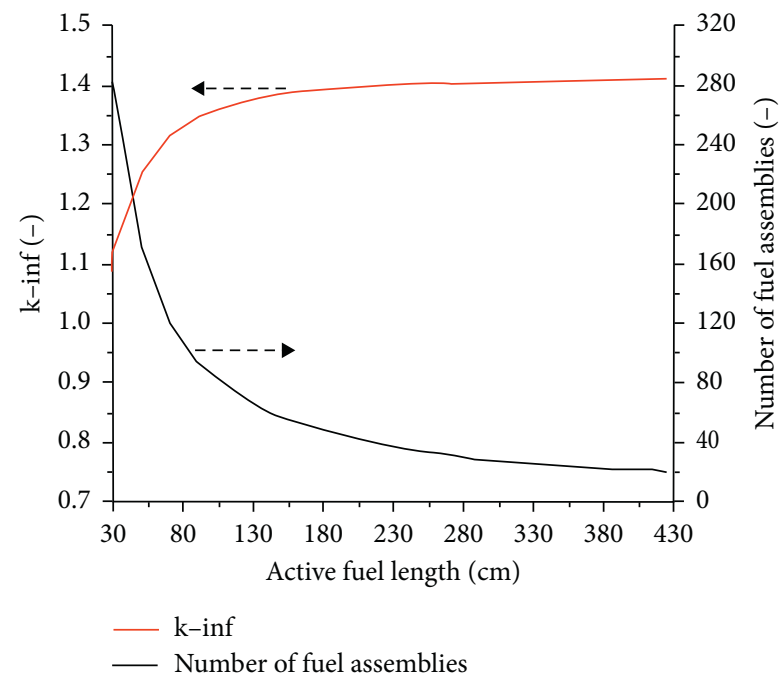

FIgURE 2: Variation of the infinite multiplication factor and required number of assemblies with increasing active fuel length.

the active fuel length. It can be seen that when the active fuel length is less than $190 \mathrm{~cm}$, the k-inf increases rapidly with the increase of the active fuel length. The k-inf value is nearly unchanged with the active fuel length greater than $190 \mathrm{~cm}$. Therefore, the active fuel length of $190 \mathrm{~cm}$ is selected, and the number of fuel assemblies in the core is determined as 45 assemblies.

3.4. Determination of the Core Loading Pattern. In order to determine the core loading pattern, a uniform power distribution and maximum fuel utilization, three core configurations with 45 fuel assemblies of the SMR are proposed in Figure 3 for further analysis. In order to achieve a uniform power distribution and maximum fuel utilization, the fuel assemblies with higher U-235 enrichment are selected with a high priority and located in the core center. Meanwhile, the fuel assemblies with lower U-235 enrichment are located peripheral core locations.

Table 3 summarizes the analysis results of the three cores. It is found that replacing the fuel assemblies with high U-235 enrichment in the inner core zone by the fuel assemblies with lower U-235 enrichment results in reducing the two-dimensional power peaking factor (PPF) in the radial direction (Fxy). The maximum two-dimensional PPFs in the axial direction (Fxz) are nearly unchanged, and the maximum three-dimensional PPFs (Fxyz) of the core models met the design criteria. But, the Fxy and the MDNBR of cores 1 and 2 did not meet the requirement. As a result, core 3 has been selected as the final design for further analysis.

3.5. Reactivity Coefficients and Reactivity Control. In order to investigate the feedbacks due to changes of fuel and coolant temperatures, the temperature reactivity coefficients have been investigated. A change in temperature of fuel material causes a change of neutron cross section, which is called the Doppler broadening effect, resulting in a change in reactivity. Meanwhile, a change in coolant temperature results in the change of moderator density, which leads to a change in reactivity of the core. For safe operation, negative values of the temperature reactivity coefficients are desirable. In the numerical analysis, the temperature of fuel and/or coolant is increased by $50 \mathrm{~K}$. For the isothermal coefficient, both temperature of fuel and coolant are increased by $50 \mathrm{~K}$.

The shutdown margins of the control rod assemblies are analyzed to ensure that the core has sufficient control rod worth. Figure 4 shows the map of the control element assemblies. The CEAs are composed of shutdown banks (S) and regulating banks $(\mathrm{R})$ located in the outer core and the inner core, respectively. The reactivity coefficients and CEAs performance of the selected core model (Core 3) at cold zero power (CZP) and hot full power (HFP) states are presented in Table 4. It can see that all coefficients are negative during the core lifetime. The CEAs of the core have sufficient shutdown margin.

\section{Transient Analysis}

The fast transient of remarkably increasing power may be caused by the ejection of control rod. If the accident occurs, the core would become supercritical and the power increases remarkably. As a result, the reactor would be out of the heat removal capability. Thus, the fuel would be melt and the core could be damaged. In this work, the transient analysis is analyzed for core model 3. The accident is initiated with that the reactor is on steady-state operation with a full power operation of $300 \mathrm{MW}$ within first $0.5 \mathrm{~s}$. The radial power distribution in the core at the beginning of the cycle of the steady state is shown in Figure 5, and the axial power distributions of three different flow channels are shown in Figure 6. These power distributions are used as initiated values for the transient analysis. When the accident happens, the core power is increased four times the nominal operating power at $0.5 \mathrm{~s}$ and the end at $1.0 \mathrm{~s}$. During the whole accident process, it is assumed that the primary circulation pumps will work normally.

The results for the fast transient are presented in Figures 7 and 8. As we can observe from Figure 7, the averaged fuel enthalpy increases and reaches its peak at 


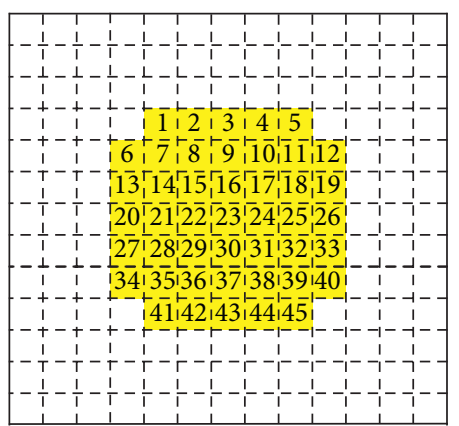

(a)

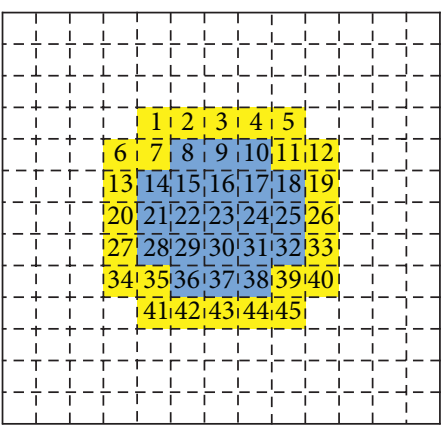

(b)

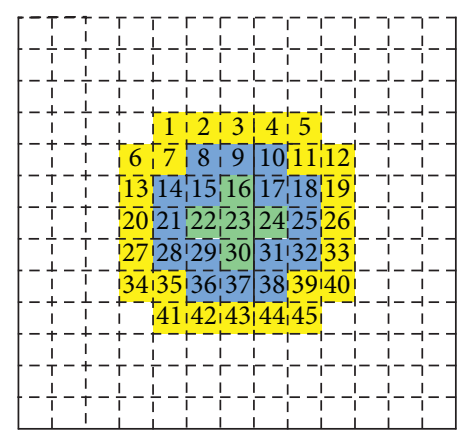

(c)

FIGURE 3: Core configurations of the SMR (yellow, blue, and green blocks represent fuel assembly assemblies with 4.45, 3.40, and 2.35 wt.\% U-235 enrichment, respectively. White block represents the water-filled position). (a) Core model 1. (b) Core model 2. (c) Core model 3.

TABLE 3: Summary of analysis results of the different core configurations.

\begin{tabular}{lccc}
\hline Parameters & Core model 1 & Core model 2 & Core model 3 \\
\hline Maximum cycle length (years) & 2.87 & 2.36 & 2.22 \\
Maximum k-eff over cycle (-) & 1.3383 & 1.2999 & 2.19 \\
Maximum 3D PPF (Fxyz) (-) & 2.48 & 1.59 & 1.2826 \\
Maximum 2D PPF (Fxy) (-) & 1.80 & 1.38 & 1.34 \\
Maximum 2D PPF (Fxz) (-) & 1.37 & 167.4 & 1.38 \\
Maximum power density (W/cm ${ }^{3}$ ) & 189.8 & 2.19 & 141.1 \\
MDNBR at nominal conditions (-) & 2.45 & 1073.5 & 3.12 \\
Maximum fuel temperature (K) & 1097.3 & 647.0 & 1001.9 \\
Maximum clad temperature (K) & 648.5 & 597.9 & 642.4 \\
Maximum coolant temperature (K) & 596.7 & 597.9 & 610.2 \\
Outlet coolant temperature (K) & 596.7 & N/A \\
Maximum critical boron concentration (ppm) & N/A & & 25.2 \\
\hline
\end{tabular}

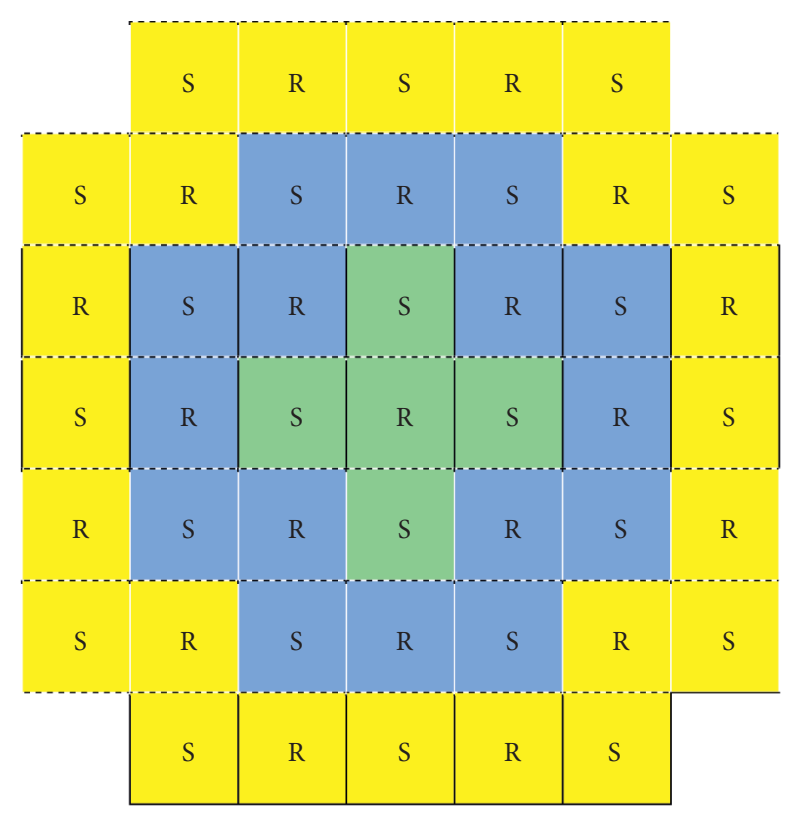

FIgURE 4: Locations of the CEAs in the active core zone.
TABle 4: Temperature coefficients and CEAs performance of the final core design.

\begin{tabular}{lc}
\hline Parameters & Values \\
\hline Temperature coefficients $(\mathrm{pcm} / \mathrm{K})$ & $<-1.91$ \\
Fuel temperature coefficient & $<-76.63$ \\
Coolant temperature coefficient & $<-79.11$ \\
Isothermal temperature coefficient & \\
CEAs performance & 0.9707 \\
Maximum k-eff over cycle for CZP (-) & 0.8669 \\
Maximum k-eff over cycle for HFP (-) &
\end{tabular}

$0.89 \mathrm{~s}$ due to the increasing core power. Afterwards, the averaged fuel enthalpy decreases due to the decreasing core power. As previously mentioned, the core flow rate keeps unchanged because of the normal operation of the coolant system. As a result, due to the fast power increase, the fuel temperature, coolant temperature, and outlet temperature of coolant increase. The highest temperatures all occur in a channel of the middle core zone. The maximum temperature of fuel and cladding are $1091.7 \mathrm{~K}$ 


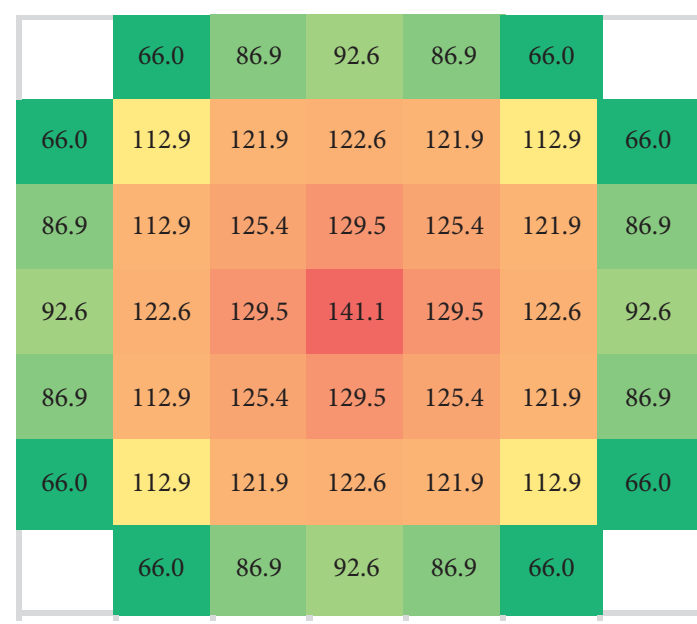

(a)

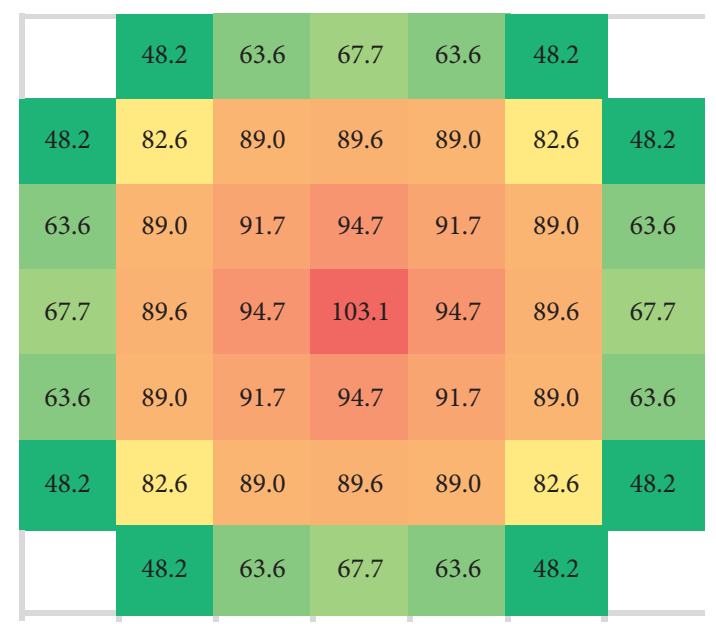

(b)

FIgURE 5: (a) The average power density distribution in the radial middle layer at the BOC $\left(\mathrm{W} / \mathrm{cm}^{3}\right)$; (b) the core average axial power density distribution at the BOC $\left(\mathrm{W} / \mathrm{cm}^{3}\right)$.

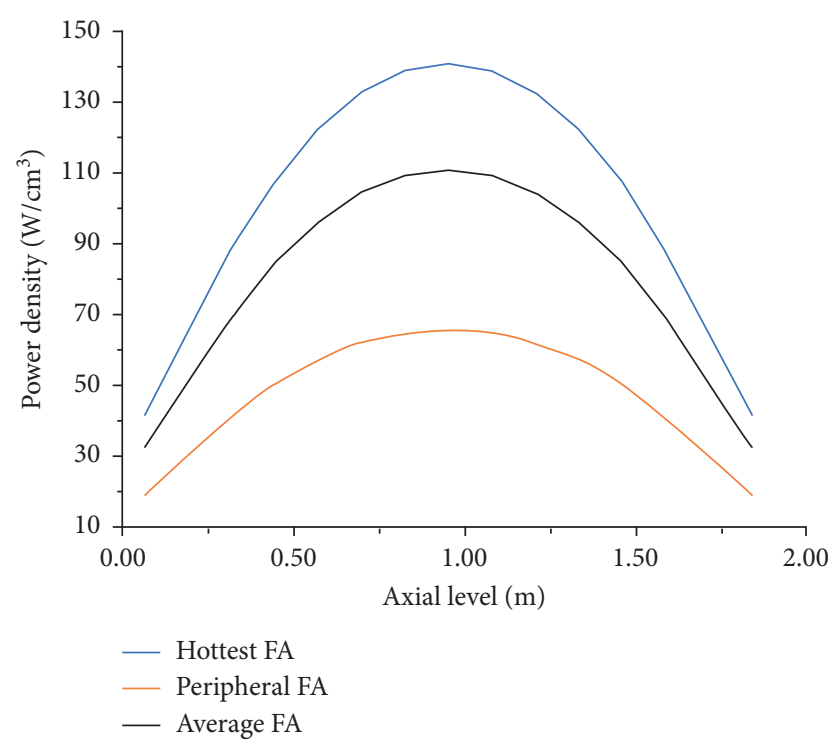

Figure 6: Axial power distribution at BOC for different flow channels.

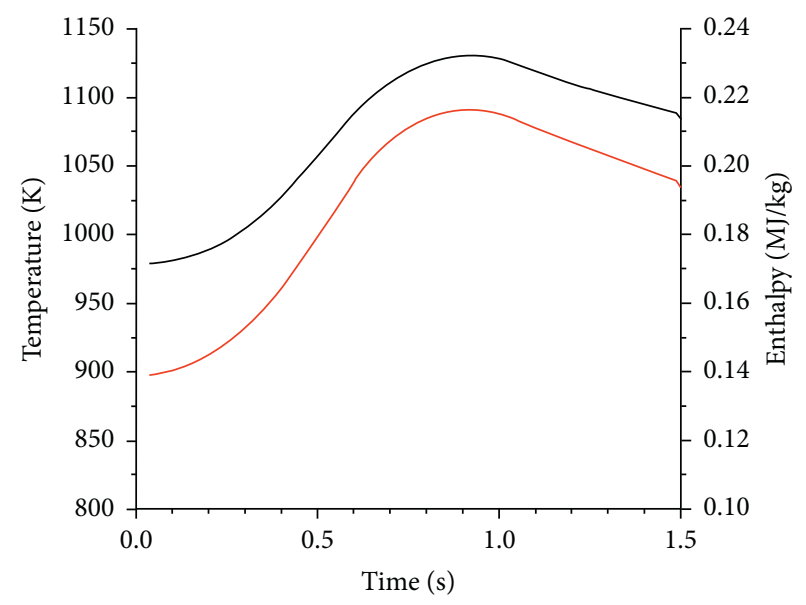

- Maximum fuel temperature

Maximum node-averaged fuel enthalpy

FIGURE 7: The maximum fuel temperature and enthalpy for the fast transient. 


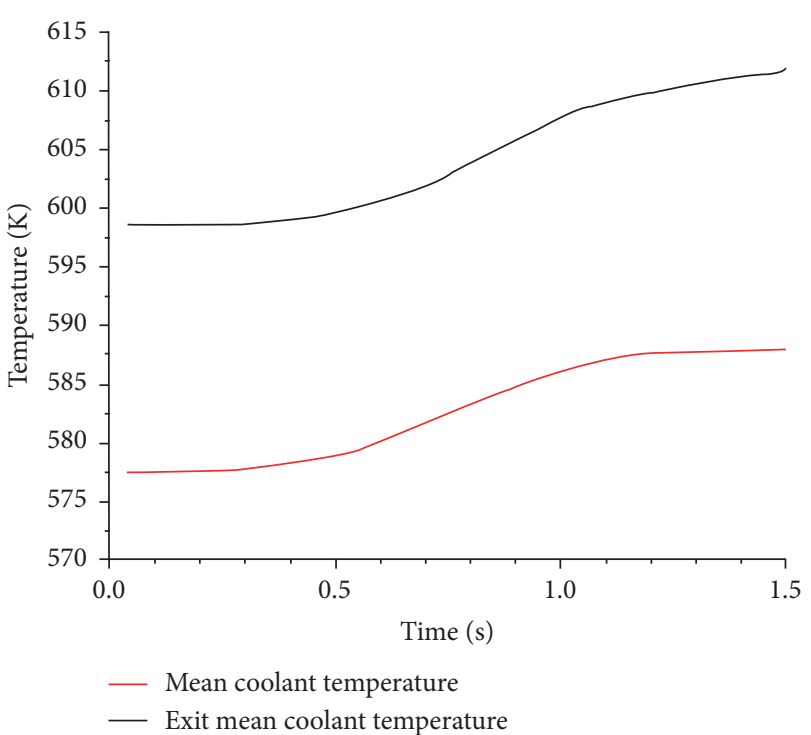

FIgURE 8: The mean and exit mean coolant temperature for the fast transient.

and $658.9 \mathrm{~K}$, respectively, which are all below the design limits. So, the reactor can very easily resist the effects of overpower transient. This reactor is safe for this unprotected overpower transient.

\section{Conclusions}

The conceptual design of a $300 \mathrm{MWt}$ SMR based on the fuel assemblies of the AP1000 reactor has been conducted. The core consists of 45 fuel assemblies with an active core height of $190 \mathrm{~cm}$ that could operate up to 2.22 years without refueling. The Doppler and moderator temperature coefficients are negative throughout the core lifetime. Maximum values of fuel, cladding, and coolant temperatures are within the design limits. The DNBR remains greater than 3.12 for the active core region. The analysis results represent that the final core design satisfies all the design criteria with significant safety margins.

\section{Data Availability}

Data used to support the findings of this study can be obtained from the corresponding author upon request.

\section{Conflicts of Interest}

The author has no conflicts of interest to declare.

\section{Acknowledgments}

This research was funded by Vietnam National Foundation for Science and Technology Development (NAFOSTED) under grant no. 103.04-2019.37. Help provided by Dr. Tran Hoai Nam of the Institute of Fundamental and Applied Sciences, Duy Tan University, Ho Chi Minh city, Vietnam, is highly appreciated. The author would like to express gratitude to Dr. Pham Nhu Viet Ha of the Institute for Nuclear
Science and Technology, VINATOM, Vietnam, for giving comments and suggestions. The author would like to express gratitude to Prof. Toru Obara of the Laboratory for Advanced Nuclear Energy, Institute of Innovative Research, Tokyo Institute of Technology, Japan, for constantly having discussion about analysis results. The author would also like to express gratitude to Msc. Nguyen Kien Cuong of the Nuclear Research Institute, VINATOM, Vietnam, for his help in performing the CORBRA-EN calculations.

\section{References}

[1] IAEA, Introduction to Small and Medium Reactors in Developing Countries, International Atomic Energy Agency, Vienna, Austria, IAEA-TECDOC-999, 1997.

[2] IAEA, Status of Small Reactor Designs without On-Site Refueling, International Atomic Energy Agency, Vienna, Austria, IAEA-TECDOC-1536, 2007.

[3] IAEA, Innovative Small and Medium Sized Reactors: Design Features, Safety Approaches and R\&D Trends, International Atomic Energy Agency, Vienna, Austria, IAEA-TECDOC1451, 2004.

[4] OECD, Small Modular Reactors: Nuclear Energy Market Potential for Near-Term Deployment, Nuclear Energy Agency Organisation For Economic Co-Operation And Development, Paris, France, NEA No. 7213, 2016.

[5] M. K. Rowinski, T. J. White, and J. Zhao, "Small and medium sized reactors (SMR): a review of technology," Renewable and Sustainable Energy Reviews, vol. 44, pp. 643-656, 2015.

[6] IAEA, Advances in Small Modular Reactor Technology Developments, A Supplement to: IAEA Advanced Reactors Information System (ARIS), International Atomic Energy Agency, Vienna, Austria, 2018 edition, 2018.

[7] U.S. Nuclear Regulatory Commission (NRC), Westinghouse AP1000 Design Control Documentation (DCD), vol. 19, Westinghouse Electric Company, Pittsburgh, PA, USA, 2011, Chapter 4.

[8] http://www.westinghousenuclear.com/Portals/0/flysheets/ NFCM-0009\%20RFA-2\%20Design.pdf.

[9] K. Okumura, T. Kugo, K. Kaneko et al., SRAC2006: A Comprehensive Neutronics Calculation Code System, Japan Atomic Energy Agency, Tokai, Japan, JAEA-Data/Code 2007004, 2007.

[10] K. Shibata, O. Iwamoto, T. Nakagawa et al., "JENDL-4.0: a new library for nuclear science and engineering," Journal of Nuclear Science and Technology, vol. 48, no. 1, pp. 1-30, 2011.

[11] K. Okumura, COREBN: A Core Burn-Up Calculation Module for SRAC2006, Japan Atomic Energy Agency, Tokai, Japan, JAEA-Data/Code 2007-003, 2007.

[12] D. Basile, M. Begbi, R. Chierici et al., "COBRA-EN, an upgraded version of the COBRA-3/IMIT code for thermalhydraulic transient analysis of light water reactor fuel assemblies and cores," Report no. 1010/1, International Atomic Energy Agency, Vienna, Austria, 1999.

[13] X. Cheng and U. Muller, Review on Critical Heat Flux in Water Cooled Reactors, Forschungzentrum Karlsruhe GmbH, Karlsruhe, Germany, 2003.

[14] D. L. Hagrman, G. A. Reymann, and R. E. Mason, "MATPROVersion 11 (Revision 2): a handbook of materials properties for use in the analysis of light water reactor fuel rod behavior," Idaho National Engineering Laboratories, Idaho Falls, ID, USA, NUREG/CR-0497 and TREE-1280, 1980. 